\title{
A Quantitative Assessment of the Morphological Characteristics of BeWo Cells as an in vitro Model of Human Trophoblast Cells
}

\author{
Una Evaluación Cuantitativa de las Características Morfológicas de las Células \\ BeWo como un Modelo in vitro de las Células de Trofoblasto Humano
}

\author{
"C.S. Abaidoo; ${ }^{* *}$ M. A. Warren; ${ }^{* *}$ P. W. Andrews \& ${ }^{* * * *}$ K. A. Boateng
}

ABAIDOO, C. S.; WARREN, M. A.; ANDREWS, P. W. \& BOATENG, K. A. A quantitative assessment of the morphological characteristics of BeWo cells as an in vitro model of human trophoblast cells. Int. J. Morphol., 28(4):1047-1058, 2010.

SUMMARY: In order to study the detailed morphology of trophoblast cells during human implantation, BeWo cells were cultured as spheroids in suspension culture. These cultures were then processed for light and electron microscopical examination. The present study showed that the BeWo spheroids consist of two cell types which are cytotrophoblast-like and syncytiotrophoblast-like. The cells with larger nuclear diameter made up only about $1 \%$ of the cell population and appear to be those of syncytiotrophoblast. Therefore the predominant cell type of the BeWo spheroids appeared to be relatively undifferentiated and cytotrophoblast-like. About $10 \%$ of the BeWo cells in the present study were mitotic, indicating a highly proliferative population. Total cell number increased about 12 times during the culture period from $107 \pm 9$ on day 1 to $1211 \pm 145$ on day 7 whereas the volume per cell increased about 2 times, from 1300 $\mu \mathrm{m}^{3}$ on day 1 to $2400 \mu \mathrm{m}^{3}$ on day 7 . Therefore overall growth of BeWo spheroids is due to both hyperplasia and hypertrophy. However, it appears that cell proliferation outstrips volumetric growth. These quantitative data show that BeWo cells grow mainly by hyperplasia and provide baseline values for further studies. In addition, the results show that BeWo cell morphology has marked similarities to that reported for human trophoblast, making it a useful model for subsequent in vitro studies.

KEY WORDS: BeWo; Trophoblast; Morphometry; Spheroids.

\section{INTRODUCTION}

Human implantation depends on a series of specific interactions between the early trophoblast cells of the blastocyst and the endometrium. However, since systematic in vivo studies are virtually impossible in the human there is an increasing need for suitable tissue culture models. Since the major events of implantation occur in the early part of pregnancy, first trimester placental tissue is likely to be the most useful source of trophoblast cells for in vitro studies (Aplin, 1996). Unfortunately, recovery of sufficient quantities of first trimester normal human placentae for such studies poses ethical as well as technical problems. In addition cytotrophoblast cells isolated from the first trimester of gestation cannot be readily propagated in culture (Irving et al., 1995; Frank et al., 2001; Abaidoo \& Warren, 2008).

An alternative approach is to examine, in vitro, the interaction of "spare" IVF embryos with endometrium.
While the use of "spare" IVF embryos for observational studies may be permitted, there are still significant ethical and practical difficulties in their use. For example, "spare" embryos are often categorized as less than optimum (as they were not used/selected for replacement). Also some of them may have been frozen for many years, which may affect their behaviour. There are also likely to be too few available for the sort of quantitative investigation needed. These and other problems have limited the study of early human trophoblast cells in the process of implantation. However the similarity of human choriocarcinoma cells in monolayer culture to normal human trophoblast cells in terms of morphology and hormone production (Pattillo et al., 1971) has enabled some investigators to use these cells to study some of the properties of trophoblast in vitro.

The BeWo human trophoblastic tumour cell line was

* Department of Anatomy, School of Medical Sciences, Kwame Nkrumah University of Science and Technology, Kumasi, Ghana.

** Department of Biomedical Science, University of Sheffield, Sheffield, S10 2TN, UK.

**** Department of Pathology, School of Medical Sciences, Kwame Nkrumah University of Science and Technology, Kumasi, Ghana. 
established in culture in 1966 (Pattillo \& Gey, 1968) from a postpartal choriocarcinoma which had been serially transplanted in the hamster cheek pouch by Hertz (1959). Its basic morphology and differentiation have been reported in monolayer culture by Grümmer et al. (1994). It has been suggested that the BeWo cell line consists of cytotrophoblastlike cells and multinuclear, giant cells which look like syncytiotrophoblast (Grümmer et al., 1990). Grümmer et al. (1990, 1994) have established BeWo multicellular spheroids in culture which have some morphological characteristics and hormonal secretions similar to BeWo monolayer cultures and normal human cytotrophoblast cells in vivo.

In vitro studies on such human trophoblastic cell lines may provide some information about the early stages of human implantation. While there are a large number of reports dealing with the hormonal secretions of BeWo cells there appears to be little published information on the ultrastructure and growth characteristics of these cells, particularly objective morphometric data. Therefore in order to provide a better understanding of the changes in BeWo cell size, organelle compliment (and therefore cell function) that occur during spheroid growth, the present study was designed to establish detailed baseline data on the morphology of BeWo cells grown in suspension culture using quantitative light microscopy. More specifically the growth characteristics of the BeWo spheroids were investigated using objective quantitative techniques as part of an investigation into a potential in vitro model for human trophoblast cells and also to make comparisons between model-based and design-based morphometric methods of volume and number estimation in order to make comparisons with published data.

\section{MATERIAL AND METHOD}

BeWo cell cultures. Choriocarcinoma cells (BeWo, Human CCL, American Type Culture Collection; Pattillo and Gey, 1968) were cultured routinely as monolayers through serial passaging in Dulbecco's Modified Eagle's Medium (DMEM, Gibco Life Technologies Limited, Paisley, Scotland) at $37^{\circ} \mathrm{C}$ in $1 \%$ carbon dioxide and $95 \%$ air in $25 \mathrm{ml}$ cell culture flasks (Costar, USA). Cells were subcultured by dispersion with $0.5 \%$ trypsin/ethylene diamine tetra-acetic acid (EDTA) (Sigma Chemicals Company, UK) at room temperature for 2-3 minutes with intermittent mechanical disruption to aid the dissociation process. A phase contrast microscope (Cambridge Instruments, UK) was used to monitor the detachment of the BeWo cells. Within two minutes the cells had detached from the flask and five mililitres of Dulbecco's Modified Eagle's Medium with Hams F12 (DMEM-F12, Gibco Life Technologies Limited, Paisley, Scotland) culturing media was added to stop further dissociation of the cells. Two millilitres of the single cell suspension was seeded into each $25 \mathrm{ml}$ cell culture flask containing $5 \mathrm{mls}$ of DMEM-F12 culturing media, the flasks were loosely stoppered and incubated at $37{ }^{\circ} \mathrm{C}$ in an atmosphere of 5\% carbon dioxide and $95 \%$ air. The culturing media was changed every $48-72$ hours. The above procedures were carried out under aseptic conditions in a class II tissue culture cabinet (Gelaire BSB4 A, Gelman SPA, Flow General, Rickmansworth, England).

Preparation of BeWo cell spheroids. For initiating spheroid culture, growing cells were harvested by using $0.5 \%$ trypsin/ EDTA at room temperature (as above). The cells were suspended in DMEM-F12 culturing media and approximately 7 x $10^{5}-1 \times 10^{6}$ cells in $10-15 \mathrm{ml}$ of DMEM\F12 were added to non-tissue culture grade sterile Petri dishes $(90 \mathrm{~mm}$ in diameter) and placed in an incubator at $37^{\circ} \mathrm{C}$ in an atmosphere of 5\% carbon dioxide and 95\% air for 16-24 hours. The media was changed every 48 hours. Large inocula resulted in a more rapid development of spheroids while using lower numbers took longer for spheroids to grow.

Tissue processing for light microscopy. The BeWo cell spheroid suspension was transferred into centrifuge tubes and spun at $1000 \mathrm{rpm}$ for 5 minutes in a bench-top centrifuge (Jouan, France). The supernatant was removed and about $5 \mathrm{ml}$ of pre-warmed $3 \%$ glutaraldehyde in $0.1 \mathrm{M}$ phosphate buffer (pH 7.4) was added to the remaining pellet containing the BeWo spheroids for $4-6$ hours. The BeWo cell spheroids were then dehydrated through sequential ethanol solutions $(70 \%$, $80 \%, 90 \%, 100 \%)$ for twenty minutes each change by centrifuging at 1000rpm and removing the supernatant at each step. The spheroids were removed, along with some ethanol, into plastic moulds. The ethanol was collected using a Pasteur pipette with a very fine tip and then JB4 embedding solution was added to the spheroids. The spheroids floated for a while then settled at the base of the mould. The moulds were covered with metal holders and left to polymerise for 24 hours under anaerobic conditions. Some of the dehydrated spheroids were cleared in chloroform for 30 minutes, infiltrated in wax for an hour and embeded in wax overnight.

Approximately $2-\mu \mathrm{m}$ thick sections were cut from every JB4 block using dry glass knives made. The sections were flattened by floating onto the surface of water at room temperature, collected on clean microscope slides and dried on a hotplate at $60{ }^{\circ} \mathrm{C}$. The slides were stained with either in $1 \%$ aqueous acid Fuschin counter-stained in $0.05 \%$ Toluidine blue or with $1 \%$ Toluidine blue alone. All slides were examined with a light microscope.

Wax blocks were sectioned at approximately $5 \mu \mathrm{m}$ and stained in $1 \%$ aqueous eosin. 
Tissue processing for electron microscopy. Some of the spheroids fixed as described above were processed for electron microscopy by embedding in Epon using standard procedures (Warren \& Bedi, 1984). Silver-gold interference coloured ultra-thin sections (about 50-70 nm thick) were cut from the same blocks as those described above using glass knives and collected on $3.05 \mathrm{~mm} 200$ mesh copper grids which were stained with uranyl acetate and lead citrate The grids were examined and micrographs taken using a Philips 301 transmission electron microscope at an accelerating voltage of 60kv. Negatives were viewed using a projection microscope.

Measurement of Section Thickness. The thickness of some of the semi-thin sections cut with the ultramicrotome was measured using a microinterferometer (Vickers Patholux interference microscope). With this instrument a beam of monochromatic light of wavelength $546 \mathrm{~nm}$ was passed through the section and the optical path difference (OPD) measured with reference to a region of empty background.

The section thickness $(\mathrm{t})$ was found from:

$$
\mathrm{t}=\mathrm{OPD} \lambda / \mu_{\mathrm{m}}-\mu_{\mathrm{a}}(\text { Goldstein \& Hartmann-Goldstein, 1974) }
$$

where

$$
\begin{aligned}
& \text { OPD = optical path difference in fraction of a wavelength } \\
& \lambda=\text { wavelength of light used } \\
& \mu_{\mathrm{m}}=\text { refractive index of media (1.51) } \\
& \mu_{\mathrm{a}}=\text { refractive index of medium in which the measurements } \\
& \text { are carried out (1.00) }
\end{aligned}
$$

The value obtained from each section was used in the appropriate calculations for the numerical densities and volume calculation as described below.

Measurement of the diameter of BeWo spheroids. The major and minor diameters of each spheroid was obtained by taking perpendicular measurements of spheroid diameter on each of 8 randomly selected spheroids using an inverted phasecontrast light microscope equipped with a calibrated eyepiece graticule. At intervals of 24 hours the spheroids were measured and put back into culture. The spheroids were fixed after seven days, processed and sectioned as described above. The major and minor diameters of the most central section of each spheroid were measured on the semi-thin sections. The sample size of 8 was found to be optimum from a pilot study.

\section{Morphometry}

Volume fraction estimates. The volume fraction $(\mathrm{Vv})$ of nucleus to cell was estimated using a point counting technique (Williams, 1977) and a $5 \mu \mathrm{m}$ square lattice (separation of points on the tissue is $6.2 \mu \mathrm{m}$ ) with the aid of a drawing tube attached to an Olympus (BH-2) microscope. At least five nonoverlapping systematically random sampled fields of view were examined for each slide of tissue. The square lattice was superimposed onto the image of the tissue and the number of points falling on the nuclei and the total number of points falling on the entire cells were recorded (Weibel, 1979). The volume fraction of nucleus to cell was calculated using the formula:

$$
\begin{aligned}
& \mathrm{Vv}_{\mathrm{v}}=\mathrm{P}_{\mathrm{n}} / \mathrm{P}_{\mathrm{c}} \text {, where } \\
& \mathrm{P}_{\mathrm{n}}=\text { total number of points on the nuclei, and } \\
& \mathrm{P}_{\mathrm{c}}=\text { total number of points on the cells. }
\end{aligned}
$$

Estimation of BeWo cell nuclear profile diameters. Major and minor diameters of the BeWo nuclear profiles were measured using a drawing tube attached to an Olympus (BH2) microscope and a digitizer tablet linked to a microcomputer using previously written software (Warren \& Bedi). Measurements were made under oil immersion at a magnification of $X 810$, determined using a stage micrometer. The mean nuclear profile diameter and its axial ratio were calculated from the values of the two axes using the equations:

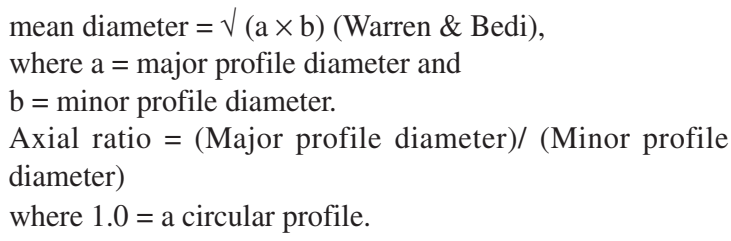

Estimation of BeWo cell spheroid area and volume. The volume of the BeWo spheroids was estimated using the Cavalieri Principle (Mayhew, 1991). A stack of parallel sections was cut through the spheroids with approximately 5 $\mu \mathrm{m}$ (microtome setting) separation between successive sections. The thickness of each of the serial sections was measured using interferometry. Sections were selected systematically from the stack of sections, taking every tenth section from a random start (Mayhew). The sampling fraction was predetermined from a pilot study. With the aid of a drawing tube attached to a microscope the areas of the BeWo spheroids were estimated at a magnification of X 810 using a point counting technique and a $5 \mathrm{~mm}$ square lattice (point separation on the tissue was $6.2 \mu \mathrm{m}$ ). The number of points falling on each cell spheroid were recorded and the areas and volumes of the spheroids were calculated using the following equation (Mayhew):

$$
\mathrm{V}=\mathrm{A} \times \mathrm{d}=\Sigma \mathrm{P} \times\{\mathrm{a}(\mathrm{p})\}^{2} \mathrm{xd},
$$

where

$$
\begin{aligned}
& \mathrm{V}=\text { volume of spheroid, } \\
& \mathrm{A}=\text { area of the spheroid, } \\
& \Sigma \mathrm{P}=\text { total number of test points falling on the }
\end{aligned}
$$


spheroid, and $\mathrm{a}(\mathrm{p})=$ the areal equivalent of one test point (distance between the points on the grid/the magnification),

$\mathrm{d}=$ interval/distance between the sections which was obtained from the summation of the section thicknesses of the sections in between.

\section{Estimation of the numerical density of BeWo cell nuclei using:}

The Disector method. The numerical density of nuclei in the BeWo cell spheroids was estimated using the disector method. This method requires a series of parallel sections, with a known distance apart to be cut through the sample (Sterio, 1984; Gundersen, 1986). A stack of semi-thin sections was cut through a sample of spheroids from which pairs of sections (Disectors) were chosen. Within each Disector the first section was designated as the reference section and the second section as the 'look up'. Data collection for the spheroids was undertaken on the Quantimet 970 image analyser (Cambridge Instruments Ltd).

Twelve pairs of semi-thin toluidine-blue-stained sections were used for each spheroid. A total of 6 spheroids were used. The 12 Disectors were taken from the serial sections in a systematic random sampling pattern. The image of the reference section (eg. section 2) was projected onto a screen and the nuclear profiles of all the nuclei within the sampling frame were traced onto acetate sheets using a water soluble pen. As there was one nucleus per cell, the nucleus was used as the counting unit for the cell. The process was repeated for the 'look-up' section (eg. section 3 ). The acetate sheet with the outline of the nuclear profiles from the reference section was superimposed onto the image of the 'look-up' section and the number of profiles of each nucleus seen in the reference section but not seen in the look-up section was counted and represented as $\mathrm{Q}^{-}$. In order to improve the efficiency of the procedure the counting was repeated on the same two sections but in the reverse direction from the first count: that is counting the number of missing profiles in section 3 (now the reference section) from the 'look-up' section (section 2) (Gundersen, 1986). In the present study, 12 Disectors were used in each direction making a total of 24 Disectors. The number of Disectors was predetermined from a pilot study. The numerical density of the BeWo cell nuclei $\left(\mathrm{N}_{\mathrm{v}}\right)$ was estimated using the formula (modified from Sterio, 1984):

Where

$$
\mathrm{Nv}=(\Sigma \mathrm{Q}-) /(\overline{\mathrm{A}} \times \Sigma \mathrm{h})
$$

$\Sigma$ Q- $=$ sum of nuclear profiles present in the reference section but missing from the 'look-up' section,

$\overline{\mathrm{A}}=$ average area of the spheroid profile,
$\Sigma \mathrm{h}=$ sum of distance between the reference section and the 'look-up' section for each disector

The Dehoff \& Rhines method. The numerical density of nuclei in the BeWo cell spheroids was also estimated using the DeHoff \& Rhines (1961), a traditional model-based, method. One semithin, toluidine blue-stained section from each of the BeWo spheroids was used. An unbiased counting frame of known area (Gundersen, 1977; Weibel) was superimposed over the image of the spheroid and the number of profiles present in the counting frame were recorded and the number per unit area determined. Only particle profiles not touching the exclusion lines were counted (Calverley et al., 1988). The measurements of the mean diameter of BeWo nuclear profiles were obtained using the digitzer, as described earlier. Estimates of the mean profile diameter obtained above give an underestimate of the true mean profile diameter therefore the Schwartz-Saltykov diameter correction procedure (Williams, 1977) was applied and the corrected mean diameter of particles obtained. The numerical density was obtained using the following formula:

where

$$
\mathrm{N}_{\mathrm{v}}=\mathrm{N}_{\mathrm{a}} / \mathrm{H}+\mathrm{t} \text { (Dehoff \& Rhines) }
$$

$$
\begin{aligned}
& \mathrm{N}_{\mathrm{v}}=\text { numerical density } \\
& \mathrm{N}_{\mathrm{a}}=\text { number of profiles per unit area } \\
& \mathrm{H}=\text { mean calliper diameter } \\
& \mathrm{t}=\text { section thickness (see below) }
\end{aligned}
$$

The numerical density of BeWo cells was calculated in 3 ways using (i) the measured section thickness, (ii) the assumed section thickness of $0.5 \mathrm{~mm}$, and (iii) assuming the thickness to be negligible (Williams).

\section{Estimation of BeWo cell number based on:}

The Disector. Missing nuclear profiles (Q') were counted as described above. The numerical density was estimated from the formula given earlier and the Nv multiplied by the volume of the spheroid $\left(\mathrm{V}_{\mathrm{s}}\right)$ to yield the total number of cells in the spheroid.

$$
\text { Total cell number }=\mathrm{N}_{\mathrm{v}} \times \mathrm{V}_{\mathrm{s}}
$$

The Fractionator. BeWo cell number per spheroid was estimated using the Fractionator (Mayhew). Missing nuclear profiles were counted on the same pairs of sections used for the Disector. The cell count was done in both directions as described earlier. The distance $h$ between the parallel sections and the volume of the spheroids are not required for this method because all of the cells in the spheroid were available for sampling. A sampling fraction of $1 / 5$ was used. The sampling scheme used in this study was employed only at 
the first level of fractionation since the spheroids were small enough to completely section them serially without the need for sub-sampling. The estimate of number $(\mathrm{N})$ was obtained from:

$$
\begin{aligned}
& \mathrm{N}=\Sigma \mathrm{Q}^{-} \mathrm{x} \text {, where } \\
& \mathrm{f}=\text { reciprocal of the sampling fraction. }
\end{aligned}
$$

Direct count of spheroids cells. Spheroids were removed at different time points from culture, measured using an eyepiece graticule and disaggregated by incubation with $0.25 \%$ trypsin/ EDTA. The number of cells in these monodispersed suspensions was simply counted directly with the aid of a dissecting microscope (Wild M32, Heerbrugg, Switzerland). The procedure was repeated by estimating cell number using a haemocytometer (improved Neubauer, Hausser Scientific Partnership, Horsham, USA) in the standard way.

Determination of mitotic cell numbers. Simple counts of mitotic cell profiles were carried out at a magnification of approximately X 1000 with an unbiased counting frame (Gundersen, 1977). The counting frame was superimposed over the image of the spheroid. The number of mitotic cell profiles and the total number of cell profiles in the frame were counted and recorded. Each spheroid was sampled systematically. The proportion of mitotic cells was then calculated. Mitotic indices were obtained for each spheroid, these were then pooled and the means and standard errors calculated per experiment.

Statistical analysis. Individual values were pooled within groups and means and standard errors were calculated for each group. Volume fraction data and nuclear profile axial ratio underwent logarithmic transformations to make the values suitable for statistical analysis. Data on nuclear profile diameters, volume and numerical density were tested directly. Data were analysed using either paired or unpaired Student's $t$ tests as appropriate to compare differences between 2 groups and a one-way analysis of variance (ANOVA) was used to examine differences in spheroid diameter over time in culture.
Number estimates obtained by the Fractionator and those derived by combining the Cavalieri principle and the Disector method were subjected to a correlation test. Untransformed data are presented in the tables.

\section{RESULTS}

Volume fraction $\left(\mathbf{V}_{\mathrm{v}}\right)$ of cell occupied by nucleus. The volume fractions of the BeWo cell occupied by nucleus are given in Table $\mathrm{I}$. The $\mathrm{V}_{\mathrm{v}}$ was numerically larger in the 7-day old BeWo spheroids (D7) than the 1-day old spheroids (D1), but this was not significant at $\mathrm{P} \leq 0.05$. The coefficient of variation for this feature in the $\mathrm{D} 1$ spheriods (5\%) was similar to the D7 group (4\%).

Nuclear profile dimensions and nuclear profile axial ratio. The nuclear profile dimensions of the $\mathrm{D} 7$ cells were larger $(\mathrm{P}<0.001)$ than the D1 spheroids (Table I). The nuclear profile axial ratio of the two groups was remarkably similar. The coefficients of variation of axial ratio for the D1 and D7 spheroids were the same (3\%).

Mean diameter of spheroids. During the period of culture, the diameter (measured directly) of spheroids increased ( $\mathrm{P}$ $<0.001$, ANOVA) linearly from a mean of $103 \pm 26 \mu \mathrm{m}$ on day one to $361 \pm 33 \mu \mathrm{m}$ on day 7 . The mean diameter after fixation and processing of the 7-day-old spheroids was 315 $\pm 28 \mu \mathrm{m}$. This was significantly $(\mathrm{P}<0.001)$ lower (by $13 \%$ ) than the mean spheroid diameter of $361 \pm 33 \mu \mathrm{m}$ obtained by direct measurement. There was a strong positive correlation $(r=0.998 ; P<0.01)$ between the spheroid diameter from the two methods.

Volume of spheroids. Volume estimates for 1 and 7-dayold spheroids for both design-based and model-based methods are given in Table II. The mean volume of the 7day-old spheroids was $2.6 \pm 0.4 \times 10^{-3} \mathrm{~mm}^{3}$. This was significantly $(\mathrm{P}<0.01)$ larger than the mean volume of the

Table I. Nuclear profile dimensions and volume fraction of nucleus to cell for the BCS group after 1 and 7 days in culture. Results are means standard errors. Values in parentheses are coefficients of variation $(\%) . \mathrm{n}=$ number of spheroids. $* * * \mathrm{P}<0.001$. Comparison between means made using unpaired Student's t-Test.

\begin{tabular}{lcc}
\hline Features & BCS/D1 n= 6 & BCS/D7 n= 6 \\
\hline V of cell occupied by nucleus & $0.189+0.004(5)$ & $0.198+0.003(4)$ \\
Major axis of nuclear profile $(\mu \mathrm{m})$ & $10.52+0.08(2)$ & $12.85+0.24^{* * *}(5)$ \\
Minor axis of nuclear profile $(\mu \mathrm{m})$ & $7.23+0.13(4)$ & $9.04+0.15^{* * *}(4)$ \\
Mean nuclear profile diameter $(\mu \mathrm{m})$ & $8.67+0.10(3)$ & $10.72+0.19^{* * *}(4)$ \\
Nuclear profile axial ratio & $1.50+0.02(3)$ & $1.48+0.02(3)$ \\
\hline
\end{tabular}


1-day-old spheroids $\left(1.4 \pm 0.2 \times 10^{-4} \mathrm{~mm}^{3}\right)$. Spheroid volume estimates obtained by the model-based method increased significantly $(\mathrm{P}<0.01)$ from $1.7 \pm 0.6 \times 10-3 \mathrm{~mm}^{3}$ to $2.9 \pm$ $1.0 \times 10^{-2} \mathrm{~mm}^{3}$. The coefficients of variation of this feature for the model-based estimates were about double those of the design-based estimates.

Numerical density estimates. The mean numerical density for spheroids fixed after 7 days in culture was significantly $(\mathrm{P}<0.001)$ lower than that of the D1 spheroids (Table II). Mean values for 1 and 7-day old spheroids from the DeHoff $\&$ Rhines and Disector methods are compared in Tables III and IV. The mean numerical density of the D1 spheroids obtained by the DeHoff \& Rhines method was $2.96 \pm 0.19 \mathrm{x}$ $10^{5} \mathrm{~mm}^{-3}$. This was significantly $(\mathrm{P}<0.001)$ lower (by 63\%) than the Disector value of $7.95 \pm 0.59 \times 105 \mathrm{~mm}^{-3}$ (Table III). There was no correlation between data from the two techniques (Table III).

For the 7-day-old spheroids, the numerical density obtained by the Disector method, using an assumed section thickness of $0.5 \mu \mathrm{m}\left(3.21 \pm 0.25 \times 10^{5} \mathrm{~mm}^{-3}\right)$ was significantly $(\mathrm{P}<0.01)$ lower than that obtained using the measured section thickness $\left(4.96 \pm 0.34 \times 10^{5} \mathrm{~mm}^{-3}\right)$ (Table IV). Similarly, the $\mathrm{N}^{\mathrm{v}}$ of the D7 spheroids obtained by the DeHoff \& Rhines method, using the measured section thickness was significantly $(\mathrm{P}<0.001)$ lower $\left(1.56 \pm 0.14 \times 10^{5} \mathrm{~mm}^{-3}\right)$, compared with the Disector value of $4.96 \pm 0.34 \times 10^{5} \mathrm{~mm}^{-}$ ${ }^{3}$ (Table IV). The Nv obtained by the DeHoff \& Rhines method using an assumed section thickness of $0.5 \mu \mathrm{m}(1.54$ $\left.\pm 0.14 \times 10^{5} \mathrm{~mm}^{-3}\right)$ was also significantly $(\mathrm{P}<0.01)$ lower than that of the Disector method $\left(3.21 \pm 0.25 \times 10^{5} \mathrm{~mm}^{-3}\right)$ but there was no correlation between these results (Table IV).

The mean numerical density derived by the DeHoff \& Rhines method assuming the section thickness to be negligible, the measured section thickness, and the assumed section thickness were found to be $1.60 \pm 0.14 \times 10^{5} \mathrm{~mm}^{-3}$,

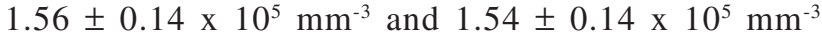
respectively (Table $\mathrm{V})$. This resulted in significant $(\mathrm{P}<0.001)$ reductions of $68 \%, 69 \%$ and $69 \%$ compared with the Disector value of $4.96 \pm 0.34 \times 10^{5} \mathrm{~mm}^{-3}$.

Table II. Volume and numerical density estimates for the BeWo spheroids after 1 and 7 days in culture.

\begin{tabular}{lcc}
\hline Features & BCS/D1 n=6 & BCS/D7 n = 6 \\
\hline Volume $\left(\mathrm{mm}^{3}\right.$; Design-based) & $1.4+0.2 \times 10^{-4}(36)$ & $2.6+0.4 \times 10^{-3 * *}(42)$ \\
Volume $\left(\mathrm{mm}^{3} ;\right.$ model-based) & $1.7+0.6 \times 10^{-3}(69)$ & $2.9+1.0 \times 10^{-2 * *}(85)$ \\
Nv $\left(\mathrm{mm}^{-5}\right)$ & $7.95+0.59 \times 10^{3}(18)$ & $4.96+0.34 \times 10^{3 * *}(17)$ \\
\hline
\end{tabular}

Results are means standard errors. Values in parentheses are coefficients of variation $(\%) . n=$ number of spheroids $* * * \mathrm{P}<0.001$. $* * \mathrm{P}<0.01$. Comparison between means made using unpaired Student's $\mathrm{t}$-Test.

Table III. Data on 1-day-old BeWo spheroids.

\begin{tabular}{lcccc}
\hline Feature & $\begin{array}{c}\text { Disector method } \\
(\text { assumed })(\mathbf{n}=\mathbf{6})(\mathbf{a})\end{array}$ & $\begin{array}{c}\text { DeHoff \& Rhines } \\
(\mathbf{n}=\mathbf{6})(\mathbf{b})\end{array}$ & $\begin{array}{c}\text { Correlation } \\
\text { r value (a vs b) }\end{array}$ & $\begin{array}{c}\text { Differences } \\
(\mathbf{\%})(\mathbf{a}-\mathbf{b})\end{array}$ \\
\hline $\begin{array}{l}\text { Numerical density } \\
\text { of BeWo cells }\left(/ \mathrm{mm}^{3}\right)\end{array}$ & $7.95+0.59 \times 10^{5}$ & $2.96+0.19 \times 10^{5}$ & 0.007 & 63 \\
$(\mathbf{a}$ vs b)
\end{tabular}

Results are means and standard errors $\mathrm{SL}=$ Significance levels. $\mathrm{n}=$ Number of spheroids. $\mathrm{t}=$ Section thickness.

Table IV. Data on 7-day-old BeWo spheroids.

\begin{tabular}{lcccccc}
\hline Feature & & $\begin{array}{c}\text { Disector method }(\mathbf{n} \\
\mathbf{=} \mathbf{6})(\mathbf{a})\end{array}$ & $\begin{array}{c}\text { DeHoff \& Rhines } \\
(\mathbf{n}=\mathbf{6}) \mathbf{( b )}\end{array}$ & $\begin{array}{c}\text { Correlation } \\
\mathbf{r} \text { value (a vs b) }\end{array}$ & $\begin{array}{c}\text { Differences } \\
(\mathbf{\%}) \mathbf{( a - b )}\end{array}$ & $\begin{array}{c}\text { SL } \\
(\mathbf{a} \text { vs b) }\end{array}$ \\
\hline $\begin{array}{l}\text { Numerical density } \\
\text { BeWo cells }\left(/ \mathrm{mm}^{3}\right)_{-}\end{array}$ & of & $4.96+0.34 \times 10^{5}$ & $1.56+0.14 \times 10^{5}$ & -0.057 & 69 & $\mathrm{P}<0.001$ \\
$\begin{array}{l}\text { Numerical density } \\
\text { BeWo cells }\left(/ \mathrm{mm}^{3}\right)\end{array}$ & of & $3.21+0.25 \times 10^{5}$ & $1.54+0.14 \times 10^{5}$ & -0.409 & 52 & $\mathrm{P}<0.01$ \\
\hline
\end{tabular}

Results are means and standard errors. $\mathrm{SL}=$ Significance levels. $\mathrm{n}=$ Number of spheroids. $\mathrm{n}=$ Data derived using the measured section thickness. $1=$ Data derived using the assumed section thickness. 
Number estimates. The number estimates obtained by combining the Disector method with Cavalieri's principle for volume determination in D1 and D7 spheroids were $107 \pm 9$ and $1211 \pm 145$ respectively (Table VI) and the values were significantly $(\mathrm{P}<0.001)$ different. The number estimates obtained by the Fractionator method were $108 \pm 9$ (D1) and $1070 \pm 60$ (D7) which was also significantly $(p<0.001)$ different. For both the 1 and 7 day-old spheroids, the number estimates obtained using the two techniques did not differ significantly $(\mathrm{P} \leq$ ) and there was a strong positive correlation $(\mathrm{r}=0.850 ; \mathrm{P}<$ $0.05)$ between the results from the two techniques. However, number estimates derived by the DeHoff \& Rhines method were significantly lower than those obtained by the design-based methods ( $43 \pm 8$ for D1 and $415 \pm 86$ for D7). The coefficients of variation of this feature for the model-based estimates were about double those of the design-based estimates.

Table V. Data on 7-day-old BeWo spheroids.

\begin{tabular}{|c|c|c|c|c|c|}
\hline Feature & $\begin{array}{l}\text { Disector method } \\
\quad(n=6)(a)\end{array}$ & $\begin{array}{c}\text { (DeHoff \& Rhines) } \\
(n=6)(b)\end{array}$ & $\begin{array}{c}\text { Correlation } \\
\text { r value (a vs b) }\end{array}$ & $\begin{array}{l}\text { Differences } \\
(\%)(a-b)\end{array}$ & $\begin{array}{c}\text { SL } \\
(\mathbf{a} \text { vs b) }\end{array}$ \\
\hline $\begin{array}{l}\text { Numerical density of BeWo cells } \\
\left(/ \mathrm{mm}^{3}\right)\end{array}$ & $4.96+0.34 \times 10^{5}$ & $1.60+0.14 \times 10^{5}$ & -0.061 & 68 & $\mathrm{P}<0.001$ \\
\hline $\begin{array}{l}\text { Numerical density of BeWo cells } \\
\left(/ \mathrm{mm}^{3}\right)\end{array}$ & $4.96+0.34 \times 10^{5}$ & $1.56+0.14 \times 10^{5}$ & -0.057 & 69 & $\mathrm{P}<0.001$ \\
\hline $\begin{array}{l}\text { Numerical density of BeWo cells } \\
\left(/ \mathrm{mm}^{3}\right)\end{array}$ & $4.96+0.34 \times 10^{5}$ & $1.54+0.14 \times 10^{5}$ & -0.061 & 69 & $\mathrm{P}<0.001$ \\
\hline
\end{tabular}

Results are means and standard errors. $\mathrm{SL}=$ Significance levels. $\mathrm{n}=$ Number of spheroids. $\$=$ Data derived by the unfolding method assuming the section thickness to be negligible. $\uparrow=$ Data derived the unfolding method using the measured section thickness. $\boldsymbol{\vee}=$ Data derived by the unfolding method using the assumed section thickness.

Table VI. Number estimates for the BeWo spheroids.

\begin{tabular}{lcc}
\hline Features & Day $1 \mathbf{~ n = 6}$ & Day 7 n = 6 \\
\hline Disector and Calvalieri & $107+9(20)$ & $1211+145^{* * *}(29)$ \\
Fractionator & $108+9(20)$ & $1070+60^{* * *}(14)$ \\
Dehoff \& Rhines and Calvalieri & $43+8(48)$ & $415+86^{* *}(51)$ \\
\hline
\end{tabular}

Results are means standard errors. Values in parentheses are coefficients of variation (\%). $\mathrm{n}=$ number of spheroids. $* * * \mathrm{P}<0.001$. $* * \mathrm{P}<0.01$.

\section{DISCUSSION}

The present study has examined the detailed morphology of a BeWo choriocarcinoma cell line using a culture system where cells grow in spheroids. This appears to be the first study of BeWo cell volume and number determination using design-based morphometric methods. Comparisons were made between design-based and model-based morphometric methods. Major differences were seen between estimates obtained by these two morphometric methods.

Quantitative and qualitative results of the present study showed that the BeWo spheroids consist of two cell types, cytotrophoblast-like and syncytiotrophoblast-like cells with the larger nuclear diameter cells making up only about $1 \%$ of the cell population. These appear to be syncytiotrophoblastlike cells. The predominant cell type of the BeWo spheroids appeared to be relatively undifferentiated and cytotrophoblast-like. This finding is in agreement with previously published reports although their conclusions were based on qualitative analyses. Aplin reported that the BeWo cell line is heterogenous with a population of approximately $1 \%$ multinuclear giant cells.
About $10 \%$ of the BeWo cells in the present study were mitotic indicating a highly proliferative population. Grümmer et al. (1990) used the bromo-deoxyuridine anti-bromo-deoxyuridine technique to detect proliferating cells in BeWo spheroids. The authors reported that proliferating cells were distributed all over spheroids at all stages of cell division and in class sizes of spheroids up to $520 \mu \mathrm{m}$ in diameter. Cell proliferation in human trophoblast cells (Genbacev et al., 1993) has been assessed using proliferative cell nuclear antigen (PCNA) antibodies specific for dividing cells (Waseem \& Lane, 1990). Genbacev et al. (1993) have shown that cytotrophoblast cells of the cell columns or clusters, some villous cytotrotrophoblast cells, and migrating extravillous trophoblast (EVT) cells from tissue explants of anchoring villi are PCNA positive. However, nuclei of syncytiotrophoblast and EVT cells outside the cell columns remained unstained (Okudaria et al., 1991). The proliferative capacity of cytotrophoblast cells has also been assessed using a different antibody raised against dividing cell nuclear antigen Ki67 (Castellucci et al., 1991; Genbacev et al., 
1992). The localization and distribution of Ki67 antigen in first trimester placentae has been reported to be the same as that for PCNA (Genbacev et al., 1993; Hermes et al., 2008). Therefore, it appears that under both in vivo and in vitro conditions migrating cytotrophoblast cells, cytotrophoblast cells in clusters, and BeWo cells retain proliferative activity.

The volume fraction of BeWo cells occupied by nucleus was not significantly different in the D7 and D1 spheroids although the nuclear profile dimensions were significantly larger in D7 cells compared with D1 cells. This was due to a corresponding increase in cytoplasmic volume during 7 days in culture as confirmed by cell volume estimates. Increased nuclear profile diameter often reflects increased transcription in the nucleus (Junqueira et al., 1992).

In the present study, determination of nuclear profile dimensions was made in order to assess the changes in size and shape of the BeWo cells during the culture period. In addition, it was used in combination with volume fraction estimates to make comparisons about both nuclear changes and alterations in other parts of the cell, such as in relative cytoplasmic or overall cell volume. While it is recognized that the nuclear profile diameter has its limitations as a direct estimator of nuclear dimensions, it was found in the present study that it was useful for interpreting $\mathrm{V}_{\mathrm{v}}$ data. Grümmer et al. (1990) reported a "high nuclear to cytoplasm ratio" when BeWo cells were put in suspension culture compared with monolayer BeWo cultures. Their conclusions were made on purely qualitative basis whereas in the present study Vvs were estimated by point counting techniques and the nuclear profile dimensions measured directly.

The present data show a significant increase in diameter between the D1 and D7 spheroids. These results are in agreement with some published reports. Grümmer et al. (1990) reported on the effect of time in culture on the diameter of BeWo spheroids grown in suspension culture. The sizes of the spheroids in their study were bigger $(226 \pm 49 \mu \mathrm{m}$ on day 1 and $524 \pm 117 \mu \mathrm{m}$ on day 9) than those of the present study. In another study Grümmer et al. (1994) reported that after 11 days in culture the mean diameter was $500 \mu \mathrm{m}$ for BeWo, $660 \mu \mathrm{m}$ for Jeg-3, and $1000 \mu \mathrm{m}$ for JAr spheroids. White et al. (1988) grew JAr cells in suspension culture and reported that the diameter of the spheroids increased with time in culture from a mean of $125.1 \pm 8.8 \mu \mathrm{m}$ on day 5 to a mean of $841.3 \pm 76 \mu \mathrm{m}$ on day 15 . The differences between values obtained in these studies and the present study was probably due to differences in content of FCS, $10 \%$ (White et al. 1988) and 15\% (Grümmer et al., 1990, 1994) compared with $2.5 \%$ used in the present study. However, Yuhas \& Li
(1978) reported that multicellular spheriod growth rates remained identical when the FCS concentration of the medium was varied between 2 and $10 \%$.

Other investigators (Yuhas \& Li; Landry et al., 1982) have reported that spheroids from other cell types such as fibrosarcoma induced by methylcholanthrene in a $\mathrm{C} 3 \mathrm{H}$ mouse (FSA) and a radiation induced mammary carcinoma from a BALB/c mouse (MCa-11) enlarge exponentially for a few days and then continue on a linear growth curve before reaching a critical diameter beyond which there is no further increase in size.

Some necrotic cells were found scattered in the spheroids in the present study, but there was no evidence of a central zone of necrosis. In addition the BeWo spheroids had small cavities which were devoid of cells adjacent to and surrounded by areas of viable cells. It is likely that the diffusion of nutrients and metabolites was still sufficient to support all cells at this stage and so few cells died by necrosis. The observation of intercellular cavities within the spheroids together with the scarce scattered pattern of necrosis formation are similar to the findings of Grümmer et al. (1990) and White et al., although in the latter study JAr cells and not BeWo cells were used. Development of central necrosis has been shown to vary considerably in spheroids of different cell lines although in most spheroid systems a central necrotic core begins to develop at diameters greater than $250 \mu \mathrm{m}$ (Soranzo et al., 1986; White et al.). For example, V79 spheroids of more than $250 \mu \mathrm{m}$ in diameter develop a necrotic core (Grümmer et al., 1990) while spheroids of other cell lines such as spheroids of human bladder carcinoma origin could reach diameters of about $500 \mu \mathrm{m}$ or even $700 \mu \mathrm{m}$ before central necrosis occurred in them (Erlichman \& Tannock, 1986; Hermes et al.).

Various cellular and extracellular processes such as hyperplasia, cellular hypertrophy, and interstitial growth may contribute to BeWo spheroid growth. Changes in spheroid diameter are not adequate for the detection of subtle changes in spheroids. Therefore, BeWo spheroid volume was estimated using a design-based morphometric method. A simple model-based method was also used in order to compare the results obtained in the present study to published reports. Spheroid volume estimates using Cavalieri's method increased, about 20 times between 1 and 7 days in culture, from $1.4 \pm 0.2 \times 10^{-4} \mathrm{~mm}^{3}$ to $2.57 \pm 0.4 \times 10^{-3} \mathrm{~mm}^{3}$. These were about 10 times lower than the estimates derived by the model-based method $\left(1.7 \pm 0.6 \times 10^{-3} \mathrm{~mm}^{3}\right.$ to $2.9 \pm 1.0 \times 10^{-}$ $\left.{ }^{2} \mathrm{~mm}^{3}\right)$. Model-based volume estimates obtained in the present study are in broad agreement with those of earlier studies (White et al.; Grümmer et al., 1990, 1994), but differ 
in detail; there was a general increase in spheroid volume and spheroid growth was linear over the culture period. However, model-based volume estimates obtained in the present study $\left(1.7 \pm 0.6 \times 10^{-3} \mathrm{~mm}^{3}\right.$ to $\left.2.9 \pm 1.0 \times 10^{-2} \mathrm{~mm}^{3}\right)$ are lower than those of previous studies $\left(6 \times 10^{-3} \mathrm{~mm}^{3}\right.$ to 7.5 x $10^{-2} \mathrm{~mm}^{3}$, reported by Grümmer et al., 1990). In these reports, unfixed spheroids were used and measurements were obtained from a phase contrast microscope fitted with an eyepiece graticule.

The reliability of model-based methods depends on how closely the model mimics the real object. The traditional model-based volume methods used by these investigators as a means of quantifying the growth of BeWo, Jar, and Jeg-3 spheroids rely on perpendicular measurements of spheroid diameter and calculation of the volume using the equation $V=4 / 3 \pi r^{3}$, which assumes that the spheroids are perfect spheres. However, BeWo spheroids differ in shape and often deviate considerably from sphericity. In addition, since the formula used for the volume estimates used the radius as part of the product, it is sensitive to even small changes in diameter. Therefore, the results obtained by this method are likely to be, at least to some extent, inaccurate and unreliable.

In order to make improved estimates of volume, it is necessary to use appropriate stereological methods of proven reliability and accuracy (Mayhew et al., 1990). The Cavalieri principle as used in this study combines a point counting technique with section thickness measurements and does not require assumptions about object shape or spatial orientation (Mayhew). The great advantage of this method is that it is design-based and not model-based and offers unbiased estimates free of simplistic and often erroneous assumptions. Application of the Cavalieri principle to a wide variety of tissues and organs has demonstrated high efficiency and reliability, although it has been reported to be time-consuming and labourintensive (Mayhew et al., 1990).

Mayhew, 1991 and others have shown that the volume of anything which can be recognized unequivocally from its profiles can be determined by generating slices and estimating volumes from the slices. The two requirements of the Cavalieri principle are; (i) a complete set of parallel sections through the entire object and the mean distance between the sections must be available, (ii) the slices are selected in a systematic random manner. The Cavalieri principle has been used to estimate the volume of brain (Mayhew et al., 1990); multicellular colon carcinoma spheroids (Bauer et al., 1995) and breast tumor volume (Ladekarl et al., 1997). These authors reported that the Cavalieri principle is an efficient, reproducible and unbiased method.
Mayhew et al. (1990) have shown that, for physical slices, the volume obtained by fluid displacement correlates extremely well with Cavalieri volume estimates. Weibe \& Laursen (1995) estimated the volume of human lung using both the Cavalieri's principle and fluid displacement. They concluded that both methods are reliable, with Cavalieri's principle being superior. Therefore the Cavalieri-based volume estimates from the present study are likely to be reliable and accurate.

The growth within BeWo spheroids were also assessed using design-based stereological methods. The results of the present study show that the volume of the spheroids increased with time in culture. The question then arises as to whether the increase is due to hypertrophy of the cells or hyperplasia. Growth within the spheroids was monitored as total number of nuclei (a measure of nuclear proliferation) and volume per nucleus (a measure of hypertrophy). The latter was estimated by calculating the volume of the spheroid associated with each nucleus; qualitative light and electron microscopic studies showed cells to be mononuclear.

There was a significant decrease (38\%) in the numerical density of BeWo cell nuclei after 7 days in culture. It is likely that an increase in the overall volume containing the cells contributed to the observed decrease in numerical density of the day 7 BeWo spheroids compared with the day 1 spheroids.

The results of the present study demonstrate that total cell number increased about 12 times during the culture period whereas the volume per cell increased about 2 times, from $1300 \mu \mathrm{m}^{3}$ on day 1 to $2400 \mathrm{~mm}^{3}$ on day 7 (combining spheroid Cavalieri volume estimates and total cell number obtained by the Fractionator method). Therefore overall growth of BeWo spheroids is due to both hyperplasia and hypertrophy. However, it appears that cell proliferation outstrips volumetric growth. The present study shows that BeWo cells proliferate and that some of the cells are lost by necrosis. However, this loss is replaced by mitosis and that the total number of cells actually increases.

Grümmer et al. (1990) used a haemocytometer to determine the cell number in BeWo multicellular spheroids. They reported that the number of cells per spheroid increased from 813 at a volume of $6 \times 10^{-3} \mathrm{~mm}^{3}$ to 8913 cells at a volume of $7.5 \times 10^{-2} \mathrm{~mm}^{3}$. Simpson et al. (1992) and Mayhew et al. (1994) using human placentae, also showed that trophoblast, stroma, and endothelial cells proliferate from the first trimester of pregnancy to term. They concluded that placental growth occurs, wholly or 
in part, by hyperplasia. Therefore the present study appears to support the notion that during gestation, cytotrophoblast cells proliferate thereby contributing to the increasing volume of the placenta.

So far nothing appears to have been reported in the literature about the use of quantitative techniques to estimate the number of cells present in BeWo spheroids. Estimates of the number of cells obtained by the Fractionator method was numerically lower for D1 spheroids and higher for D7 spheroids when compared with those obtained by the haemocytometer and the dissecting microscope. However, the estimates obtained by combining the Disector method and the Cavalieri's principle for volume estimation were not significantly $(\mathrm{P} \leq 0.05)$ different from the Fractionator values.

The great advantage of the combined Cavalieri principle and the Disector method is that they are both design-based and not model-based. Mayhew et al. (1994) studied the growth of the human placenta during gestation using numerical density estimates based on the Disector and the corresponding volume estimates. West \& Gundersen (1990) used this technique to estimate the number of neurons in the human hippocampus. Ladekarl et al. (1997) estimated the total number of cancer cell nuclei in breast cancer tumors using the optical Disector and the volume of the tumor (estimated by the Cavalieri principle). They concluded that the estimates obtained by this technique are unbiased and highly reproducible.

There was no correlation between the results obtained by the Disector and the model-based method in the present study. The reasons for this remain unclear but it appears to suggest that as well as producing different absolute values, the two methods are different in distribution estimates. Similar results were obtained by Akbar (1991) in the nervous system.

Comparison of numerical density values for D7 spheroids obtained by the Disector was made using both assumed $(0.5 \mu \mathrm{m})$ and measured section thicknesses. These results showed that the numerical density estimates based on the assumed section thickness were consistently lower, compared with values based on the measured section thickness. Since the measured section thickness was found to be consistently less than the assumed section thickness, the lower numerical density estimates was as predicted. The importance of accurately determining section thickness is therefore apparent, especially for the Disector where it contributes to the product in the denominator. In contrast, the Fractionator does not require the thickness of the individual sections.
As above, the results for the DeHoff \& Rhines method showed estimates using measured section thickness to be consistently lower than those where $t=0$ but numerically marginally higher compared with values based on the assumed section thickness. This was entirely to be expected from the formula used for the numerical density estimation. Also the correlation of the data based on the three section thicknesses was excellent.

As mentioned above, the Disector and the Cavalieri methods for volume estimation both require serial sectioning and knowledge of the distance between the sections, usually found from the true section thickness. It is therefore necessary to measure the exact thickness of the sections being used for both methods. In the present study section thicknesses were measured by interferometry. This method was chosen because of its accuracy and reproducibility (Goldstein \& Hartmann-Goldstein; Williams). A drawback of this method, however, is that sections have to be measured before staining and mounting. A solution to this problem was reported by Bedi (1987). He showed that a light vertical cut can be made on one side of the face of the block dividing it into small and large portions. The smaller piece is collected and its thickness measured while the larger one is stained and mounted for the appropriate measurement.

It is well documented that the true thickness of sections is often different from the microtome setting (Bedi; Akbar, 1991; Warren, 1992). Such differences may be due to variations in mechanical and thermal changes and compression during sectioning (Mori \& Christensen, 1980; Ohno, 1980). Using interferometry, the measured section thickness of semi-thin Araldite-embedded sections (mean $0.44 \mu \mathrm{m}$, range $0.16-0.80 \mu \mathrm{m}$ ) and ultra-thin (mean $54.4 \mathrm{~nm}$, range 43.4-71.2 $\mathrm{nm}$ ) were found to be an underestimate of the microtome setting $(0.5 \mu \mathrm{m})$ (Warren, 1992). The estimation of section thickness from interference colours has also been reported to be subject to large and inconsistent errors (Williams, 1977). Neither the advance setting of the ultramicrotome nor the evaluation of section thickness by observing the reflected light interference colour can be relied upon. Therefore the actual section thickness of sections for quantitative studies must be verified by measurement.

In conclusion, these quantitative data show that BeWo cells grow mainly by hyperplasia and provide baseline values for further studies. In addition, the results show that BeWo cell morphology has marked similarities to that reported for human trophoblast, making it a useful model for subsequent in vitro studies. Furthermore results of the present study reinforce the need to base conclusions on objective unbiased estimates rather than traditional model-based methods. 
ABAIDOO, C. S.; WARREN, M.A.; ANDREWS, P. W. \& BOATENG, K. A. Una evaluación cuantitativa de las características morfológicas de las células BeWo como un modelo in vitro de las células de trofoblasto humano. Int. J. Morphol., 28(4):1047-1058, 2010.

RESUMEN: En un cultivo de suspensión se estudió la morfología de las células durante la implantación del trofoblasto humano, células BeWo. Estos cultivos fueron procesados y examinados a través de microscopía de luz y electrónica. El estudio mostró que los esferoides BeWo constan de dos tipos de células, citotrofoblasto y sincitiotrofoblasto. Las células con mayor diámetro nuclear parecen ser los sincitiotrofoblasto que representaban sólo el $1 \%$ de la población celular. Por tanto, el tipo celular predominante de los esferoides BeWo parecían ser relativamente indiferenciados como citotrofoblasto. Alrededor del $10 \%$ de las células BeWo fueron mitóticas, lo que indica una población altamente proliferativa. El número de células totales aumentó alrededor de 12 veces durante el período de cultivo de $107 \pm 9$ días en el día 1 a $1211 \pm 145$ en el día 7, mientras que el volumen de la célula creció alrededor de 2 veces, desde $1300 \mathrm{~mm}^{3}$ el día 1 hasta $2400 \mathrm{~mm}^{3}$ el día 7. Por lo tanto, el crecimiento global de esferoides BeWo se debe tanto a la hiperplasia como a la hipertrofia. Sin embargo, parece que la proliferación celular supera al crecimiento volumétrico. Estos datos cuantitativos muestran que las células BeWo crecen principalmente por hiperplasia y proporcionan valores de referencia para estudios posteriores. Además, los resultados muestran que la morfología celular BeWo ha marcado similitudes con los reportado para el trofoblasto humano, por lo que es un modelo útil para posteriores estudios in vitro.

\section{PALABRAS CLAVE: BeWo; Trofoblasto; Morfometría; Esferoides.}

\section{REFERENCES}

Abaidoo, C. S. \& Warren, M. A. Morphological And Behavioural Features Of BeWo Cells Grown On Matrigel Offers A Model For Human Cytotrophoblast Cells During Early Implantation. J. of Science and Technology, 28(1):4-16, 2008.

Akbar, G. N. K. A quantitative histological study on the brain morphology of rats reared artificially and subjected to different environmental conditions. Ph.D Thesis. The University of Sheffield, 1991.

Aplin, J. D. The cell biology of human implantation. Placenta, 17(5-6):269-75, 1996.

Bauer, J.; Gries, W. \& Bahmer, F. A. Volume estimation of multicellular colon carcinoma spheroids using Cavalieri's principle. Pathol. Res. Pract., 191(12):1192-7, 1995.

Bedi, K. S. A simple method of measuring the thickness of semithin and ultra-thin sections. J. Microsc., 148(1): 107-12, 1987.

Calverley, R. K. S.; Bedi, K. S. \& Jones, D. G. Estimation of the numerical density of synapses in rat neocortex. J. Neurosci. Methods, 23:195-205, 1988.

Castellucci, M.; Classen-Linke, I.; Mülhauser, J.; Kaufmann, P.; Zardi, L. \& Chiquet-Ehrismann, R. The human placenta: a model for tenascin expression. Histochemistry, 95(5):449-58, 1991.

DeHoff, R. T. \& Rhines, F. N. Determination of the number of particles per unit volume from measurements made on random plane sections: the general cylinder and the and the ellipsoid. Am. Inst. Min. and Met. Eng., 221:975-96, 1961.

Erlichman, C. \& Tannock, I. F. Growth and characterization of multicellular tumor spheroids of human bladder carcinoma origin. In vitro Cell Dev. Biol., 22:449-56, 1986.
Frank, H. G.; Morrish, D. W.; Pötgens, A.; Genbacev, O.; Kumpel, B. \& Caniggia, I. Cell culture models of human trophoblast: primary culture of trophoblast--a workshop report. Placenta, 22:S107-9, 2001.

Genbacev, O.; Schubach, S. A. \& Miller, R. K. Villous culture of first trimester human placenta-model to study extravillous trophoblast (EVT) differentiation. Placenta, 13:439-61, 1992.

Genbacev, O.; Jensen, K. D.; Powlin, S. S. \& Miller, R. K. In vitro differentiation and ultrastructure of human extravillous trophoblast (EVT) cells. Placenta, 14:463-75, 1993.

Goldstein, D. J. \& Hartmann-Goldstein, L. J. Accuracy and precision of a scanning and integrating microinterferometer. J. Microsc., 102:143-64, 1974.

Grümmer, R.; Hohn, H. P. \& Denker, H.W. Choriocarcinoma cell spheroids: an in vitro model for the human trophoblast. Trophoblast. Res., 4:97-111, 1990.

Grümmer, R.; Hohn, H. P.; Mareel, M. M. \& Denker, H. W. Adhesion and invasion of three human choriocarcinoma cell lines into human endometrium in a three-dimensional organ culture system. Placenta, 15(4):411-29, 1994.

Gundersen, H. J. G. Notes on the estimation of the numerical density of arbitrary profiles: the edge effect. J. Microsc., 111:219-223, 1977.

Gundersen, H. J. Stereology of arbitrary particles. A review of unbiased number and size estimators and the presentation of some new ones, in memory of William R. Thompson. $J$. Microsc., 143:3-45, 1986.

Hermes, C.; Azevedo, J. F.; Araujo, E. J. A. \& Santana, D. M. G. Intestinal Ascending Colon Morphometrics in Rats Submitted to Severe Protein Malnutrition. Int. J. Morphol., 26(1):5-11, 2008. 
Hertz, R. Choriocarcinoma of women maintained in serial passage in hamster and rat. Proc. Soc. Exp. Biol. Med., 102:77-80, 1959.

Irving, J. A.; Lysiak, J. J.; Graham, C. H.; Hearn, S.; Han, V. K. \& Lala, P. K. Characteristics of trophoblast cells migrating from first trimester chorionic villus explants and propagated in culture. Placenta, 16(5):413-33, 1995.

Junqueira, L. C.; Carneiro, J. \& Kelley, R. O. Basic Histology. $7^{\text {th }}$ ed. Norwalk, Appleton and Lange, 1992. pp.25-6.

Ladekarl, M.; Jensen, V. \& Nielsen, B. Total number of cancer cell nuclei and mitoses in breast tumors estimated by the optical disector. Anal. Quant. Cytol. Histol., 19(4):329-37, 1997.

Landry, J. A.; Freyer, J. P. \& Sutherland, R. M. A model for the growth of multicellular spheroids. Cell Proliferation, 15:585-94, 1982.

Mayhew, T. M.; Mwamengele, G. L. M. \& Dantzer, V. Comparative morphometry of the mammalian brain: estimates of cerebral volumes and cortical surface areas obtained from macroscopic slices. J. Anat., 172:191-200, 1990.

Mayhew, T. M. The new stereological methods for interpreting functional morphology from slices of cells and organs. Exp. Physiol., 76:639-65, 1991.

Mayhew, T. M.; Wadrop, E. \& Simpson, R. A. Proliferative versus hypertrophic growth in tissue subcompartments of human placental villi during gestation. J. Anat., 184:535-43, 1994.

Mori, H. \& Christensen, K. Morphometric analysis of Leydig cells in the normal rat testis. J. Cell Biol., 84:340-54, 1980.

Ohno, S. Morphometry for determination of size distribution of peroxisomes in thick sections by high voltage electron microscopy. In: studies of section thickness. J. Electron Microsc., 29:230-5, 1980.

Okudaria, Y.; Matsui, Y. \& Kanoh, H. Morphological variability of human trophoblasts in normal and neoplastic conditions. In: Soma, H. (Ed). Placenta: Basic Research for Clinical Application. International conference on Placenta, Tokyo, Basel - Karger, 1991. pp.171-87.

Pattillo, R. A. \& Gey, G. O. The establishment of a cell line of human hormone-synthesizing trophoblastic cells in vitro. Cancer Res., 28:1231-6, 1968.

Pattillo, R. A.; Gey, G. O.; Delfs, E.; Huang, W. Y.; Hause, L.; Garancis, J.; Knoth, M.; Amatruda, J.; Bertino, J.; Friesen, H. G. \& Mattingly, R. F. The hormone-synthesizing trophoblastic cell in vitro: A model for cancer research and placental hormone synthesis. Ann. N. Y. Acad. Sci., 172:288-98, 1971.

Simpson, R. A.; Mayhew, E. \& Barnes, P. R. From 13 weeks to term, the trophoblast of human placenta grows by the continous recruitment of new proliferative units: A study of nuclear number using the Disector. Placenta, 13:501-12, 1992.
Soranzo, D. C.; Della Torre, G. \& Ingrosso, A. Formation growth and morphology of multicellular tumor spheroids from human colon carcinoma cell line (LoVo). Tumori., 72:459-67, 1986.

Sterio, D. C. The unbiased estimation of the number and sizes of arbitrary particles using the disector. J. Microsc., 134:127-36, 1984.

Warren, M. A. \& Bedi, K. S. A quantitative assessment of the development of synapses and neurons in visual cortex of control and undernourished rats. J. Comp. Neurol., 227:104-8, 1984.

Warren, M. A. Simple morphometry of the nervous system. In: Quantitative methods in neuroanatomy. Stewart, M. G. (Ed). England, Chichester, 1992. pp.211-47.

Waseem, N. \& Lane, D. P. Monoclonal antibody analysis of the proliferating cell nuclear antigen (PCNA). Structural conservation and the detection of a nucleolar form. J. Cell Sci., 96:121-9, 1990.

Weibel, E. R. Stereological Methods. New York, Academic Press, 1979.

West, M. J. \& Gundersen, H. J. G. Unbiased stereological estimation of the number of neurons in the human hippocampus. J. Comp. Neurol., 296:1-22, 1990.

White, T. E.; Saltzman, R. A.; Di Sant'Agnese, P. A.; Keng, P. C.; Sutherland, R. M. \& Miller, R. K. Human choriocarcinoma (Jar) cells grown as multicellular spheroids. Placenta, 9(6):583-98, 1988.

Weibe, B. M. \& Laursen, H. Human lung volume, alveolar surface area, and capillary length. Microsc. Res. Tech., 32(3):255-62, 1995.

Williams, M. A. Quantitative methods in biology. In: Practical Methods in Electron Microscopy. Glauert, A. M. (Ed.). Amsterdam, North-Holland, 1977.

Yuhas, J. M. \& Li, A. P. Growth fraction as the major determinant of multicellular tumor spheroid growth rates. Cancer Res., 38:152832, 1978.

Correspondence to:

Dr. Chrissie Stansie Abaidoo

Department of Anatomy

School of Medical Sciences

Kwame Nkrumah University of Science and Technology

Kumasi

GHANA

Email: chrissiestansieabaidoo@yahoo.co.uk

Received: 01-06-2010

Accepted: 23-09-2010 